\title{
Research on distributed mathematical model of liquid cargo ship
}

\author{
Fan Shihao
}

\begin{abstract}
The width of liquid cargo ship(LCship) is an important parameter in ship design. The width data of LCship are collected, the mathematical model of the width of LCship is established, and the formula for calculating the width of LCship is constructed. The results show that the width of LCship obeys the Weibull distribution. Through the transformation, the nonlinear liquid cargo ship Weibull distribution is transformed into a linear expression, and the parameters in the Weibull distribution of the are calculated.
\end{abstract}

Index Terms - liquid cargo ship, width, mathematical model.

\section{INTRODUCTION}

Any vessel has a length and width. It has different width if ship is different. The width of the ship is also different in different areas. Scientists from all over the world have studied the width of the ship over thousand years. Chen.[1] discussed the problem of fluid-solid coupling deformation of large ships in random sea condition, and it is considered that the ship width has an influence on the fluid-solid coupling deformation of ships. Xinyun[2] study the function of ship width in wave, and show the calculation results in the tables or figures. Xin[3] given fluid-solid coupling differential equation, and obtained first-order approximate result . Xin[4] given numerical algorithm by using parallel computing method. Song[5] considered the effect of ship width on propulsion, and gave force algorithm with ship width. Tezdogan,[6] discussed the effect of ship width on ship protection. The calculation formula and steps are given. McEntee [7] analyzed the influence of ship width on friction, and thought that ship width can improve friction. Lewthwaite [8] considered the relationship between ship width and viscous force, and obtained the viscous calculation method related to ship width. Schultz [9] studies the relationship between ship resistance and ship width, and gives the corresponding calculation results.

In this paper, the mathematical model of liquid cargo ship width distribution [9] is considered and the corresponding calculation principle is given.

\section{DATA PROCESSING}

The width data of 2408 liquid cargo ship is collected, and then the frequency is calculated according to the width data. The results show in Fig.1. From figure 1, it can be seen that the frequency is the largest when the width of liquid cargo ship is $20 \mathrm{~m}$. When the width of the liquid cargo ship is more than 40 $\mathrm{m}$, the frequency fluctuates. The approximate distribution of width can be observed from the frequency histogram. The distribution of liquid cargo ship width is non-negative and the

Fan Shihao,Shanghai Xuhui high school, Shanghai 200030, China distribution of liquid cargo ship width is asymmetrical. The distribution of liquid cargo ship width increases first and then decreases slowly to 0 .

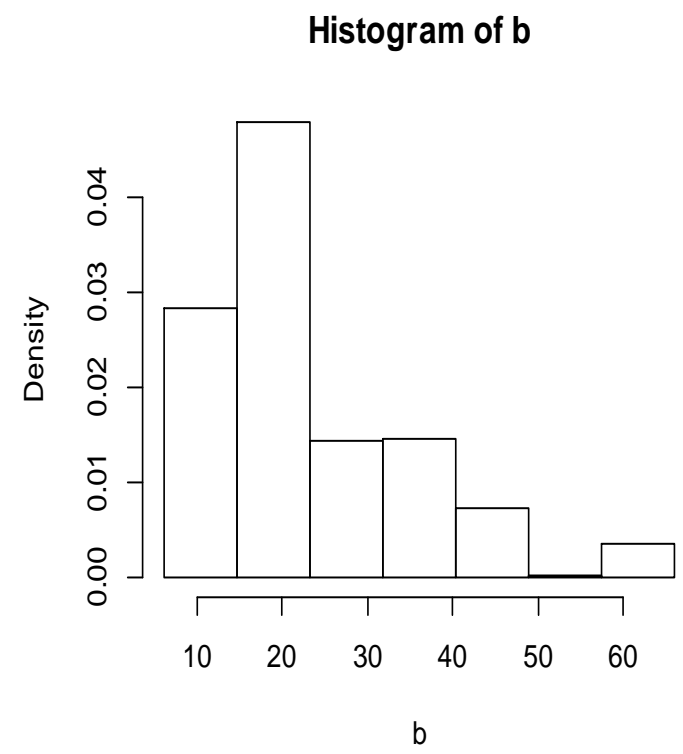

Fig.1 wide frequency histogram

\section{MATHEMATICAL MODEL OF TANKER WIDTH}

According to the above analysis results, the width of the tanker approximately obeys the Weibull distribution. The probability density of Weibull distribution is:

$$
f(x)=\left\{\begin{array}{cc}
\frac{b}{a}\left(\frac{x}{a}\right)^{b-1} e^{-\left(\frac{x}{a}\right)^{b}} & x>0 \\
0 & x \leq 0
\end{array}\right.
$$

here $a, b$ are the parameters, and $a>0$. If $x=x i>0$, at point $x i$, $\mathrm{i}=1,2, \ldots, \mathrm{N}$. we have:

$$
f\left(x_{i}\right)=\frac{b}{a}\left(\frac{x_{i}}{a}\right)^{b-1} e^{-\left(\frac{x_{i}}{a}\right)^{b}} \quad i=1,2, . ., N
$$

from negative to infinity, the distribution function of Weibull distribution integration is

$$
F(x)=1-\exp \left(-(x / a)^{b}\right)
$$

or

$$
1-F(x)=\exp \left(-(x / a)^{b}\right)
$$

By using Logarithm theory, above equation can be written as 


$$
\ln [1-F(x)]=-(x / a)^{b}
$$

or

$$
-\ln [1-F(x)]=x^{b} a^{-b}
$$

By using Logarithm theory again:

$$
\ln [-\ln (1-F)]=-b \ln a+b \ln x
$$

Take $\mathrm{c}=-\mathrm{b} * \ln (\mathrm{a}), \mathrm{z}=\ln \mathrm{x}$, we have linear formula about $\mathrm{a}$ and $\mathrm{b}$.

$$
y=c+b z
$$

here

$$
y=\ln [-\ln (1-F)], c=-b \ln a, z=\ln x
$$

Using about formula and data, $\mathrm{c}$ and $\mathrm{b}$ are obtained by using linear regression. We have

$$
a=\exp \left(-\frac{c}{b}\right)
$$

\section{NUMERICAL CALCULATION}

According to data given and formula, the steps to find $\mathrm{a}$ and $\mathrm{b}$ are:

1)Calculate frequency $f(x)$;

2) Calculate $F$ by sum of $f(x)$;

3)Calculate $a$ and $b$ by using linear regression method.

The calculation results are shown in the Fig.2. In the Figure, straight line is linear regression $y=c+b z$, the dotted line is the measurement data. The corresponding regression indexes are listed in Table 1

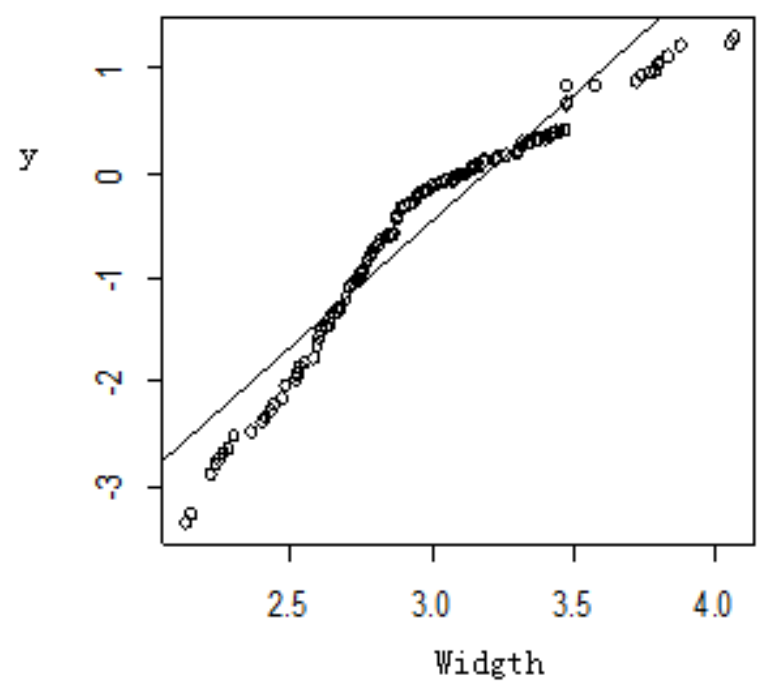

Fig.2, Scatter plot and Fitting straight line

Table 1. regression indexes results

\begin{tabular}{|c|c|c|c|c|c|c|}
\hline $\begin{array}{c}\text { paremet } \\
\mathrm{er}\end{array}$ & $\begin{array}{c}\text { Estimat } \\
\text { ed }\end{array}$ & $\begin{array}{c}\text { Standar } \\
\mathrm{d} \text { error }\end{array}$ & tvalue & $\begin{array}{c}\text { Residual } \\
\text { standard } \\
\text { deviation }\end{array}$ & $\mathrm{R}$ & $\mathrm{a}$ \\
\cline { 1 - 5 } $\mathrm{c}$ & -7.75 & 0.112 & -68.7 & 0.28 & 0.92 & 24.2 \\
\cline { 1 - 5 } $\mathrm{b}$ & 2.43 & 0.037 & 65.1 & & & \\
\hline
\end{tabular}

From table, we have linear regression results:

$$
y=-7.75174+2.43050 z
$$

The estimated value of $\mathrm{c}$ is -7.75174 , the standard deviation is
0.11272 , the value of $\mathrm{T}$ is -68.77 , and the value of $\mathrm{P}$ is 0.000 . The results show that intercept a is significantly not 0 ; the estimated value of slope B is 2.43050 , the standard deviation is 0.03733 , the value of $\mathrm{T}$ is 65.11 , and the value of $\mathrm{P}$ is 0.000 . The results show that slope $\mathrm{k}$ is significantly not 0 . The standard deviation of residuals is 0.285 , the determination coefficient of regression is 0.9849 , and the adjustment determination coefficient is 0.9278 , which indicates that the result of regression equation is ideal. From the calculation, Lamda is 24.27289, which shows that the width of the model obeys the Weibull distribution w $(2.43050,24.27289)$ with the parameter $(2.43050,24.27289)$. It can be seen from the square figure 3 of the regression that, on the whole, the residual is distributed near 0 , and the maximum value of the residual square is reduced from 4.775719 to 0.7249141 , indicating that the regression effect is very good.

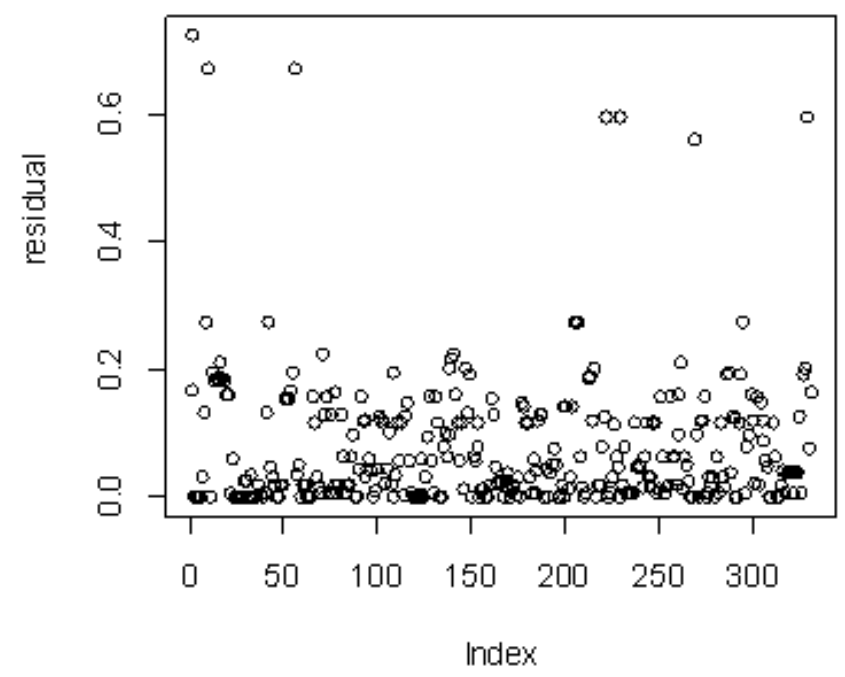

Fig.3.Residual square

By using formula

$y=\ln [-\ln (1-F)], c=-b \ln a, z=\ln x$

we have

$1-F=\exp (-\exp (y)) \quad a^{b}=\mathrm{e}^{-c} \quad x=e^{z}$

or

$1-F=\exp (-\exp (-7.75174+2.43050 \mathrm{z}))$

$=\exp (-\exp (-7.75174+2.43050 \ln x))$

or

$$
\begin{aligned}
& F=1-\exp \left[-x^{2.43050} / \exp (7.75174)\right] \\
& =1-\exp \left[-x^{2.43050} / 24.273^{2.43050}\right] \\
& =1-\exp \left[-(x / 24.273)^{2.43050}\right]
\end{aligned}
$$

or write as

$$
F=1-\exp \left[-(x / 24.273)^{2.43050}\right]
$$

It is the distribution function of the liquid cargo ship width. 


\section{CONCLUSION}

By collecting the liquid cargo ship width data, the statistical characteristics of the liquid cargo ship width are studied. From the frequency statistical chart, it can be known that the liquid cargo ship width width approximately obeys the Weibull distribution. Weibull distribution can be transformed into linear expression for parameters, so it is convenient to calculate by using regression method[10] . Through regression calculation, the parameters of Weibull distribution are obtained, and the calculation formula is obtained.

\section{ACKNOWLEDGMENT}

The paper is financially supported by China national natural science foundation (No.51139005)..

\section{REFERENCES}

[1]]Chen Zhao, zhang Shesheng, Li Yuguang, Research on large deviation algorithm of fluid structure coupling deformation of large ships under random sea conditions [J], computer science, 2016(z6), 60-98.

[2]Xinyun Liu, Xincong zhou, Shesheng Zhang, and Yuguang Li,Large Ship Fluid-Structure Coupling Deformation Calculation Based on Large Deviation Theory[C], Proceeding of DCABES 2015, 18-20 Aug.20154, Guizhou, China., 407-410.

[3]Xin Chen, XinCong Zhou, Shesheng Zhang, Dan Li, A numerical fluid-solid coupling model for the dynamics of ships in atrocious sea conditions[J], Journal of Algorithms \& Computational Technology,2015,Vol. 9 No. 2, 163-175.

[4]Xin Chen, Mengyu Li, and Shesheng Zhang, A Parallel Algorithm of Non-Linear Fluid-Solid Coupling Problem for Hydrofoil[J], Journal of Algorithms \& Computational Technology,2014,Vol. 8 No. 3, 249-266.

[5]Song, Soonseok, Penalty of hull and propeller fouling on ship self-propulsion performance[J],

Applied Ocean Research, v 94, January 2020, 1-24..

[6]T. Tezdogan, Y.K. Demirel, An overview of marine corrosion protection with a focus on cathodic protection and coatings[J], Brodogradnja, 65 (2014), pp. 49-59

[7]W. McEntee, Variation of frictional resistance of ships with condition of wetted surface[J], Trans. Soc. Nav. Arch. Mar. Eng., 24 (1915), pp. 37-42

[8]J. Lewthwaite, A. Molland, K. Thomas, An investigation into the variation of ship skin frictional resistance with fouling[J], Trans. Royal Instit. Naval Archit., 127 (1985), pp. 269-284.

[9]M.P. Schultz, Effects of coating roughness and biofouling on ship resistance and powering[J], Biofouling, 23 (5) (2007), pp. 331-341.

[10]Song Soonseok,Demirel Yigit Kemal,Atlar Mehmet, Penalty of hull and propeller fouling on ship self-propulsion performance[J], Applied Ocean Research, 2020, Vol.94, No.1, 1-24. 